\title{
Rasd1 interacts with Ear2 (Nr2f6) to regulate renin transcription
}

\author{
Jen Jen Tan ${ }^{1,2}$, Shufen Angeline Ong ${ }^{1}$, Ken-Shiung Chen ${ }^{1 *}$
}

\begin{abstract}
Background: The Rasd1 protein is a dexamethasone induced monomeric Ras-like G protein that oscillates in the suprachiasmatic nucleus (SCN). Previous studies have shown that Rasd1 modulates multiple signaling cascades. However, it is still unclear exactly how Rasd 1 carries out its function. Studying protein-protein interactions involving Rasd1 may provide insights into its biological functions in different contexts.

Results: To further explore the molecular function of Rasd1, we performed a yeast two-hybrid screen and identified Ear2, a negative regulator of renin transcription, as an interaction partner of Rasd1. We validated the interaction in vitro and in transfected COS-7 cells. We further confirmed the interaction of endogenous Rasd 1 and Ear2 from HEK293T cell and mouse brain extract. Rasd1 inhibited transcriptional repression by Ear2 on a renin promoter-luciferase reporter construct both in the presence and absence of all-trans-retinoic acid. Moreover, realtime RT-PCR showed upregulation of endogenous renin transcription in As4.1 cells over-expressing Rasd1. We demonstrated that the ligand binding domain of Ear2 is required for physical and functional interaction between the two proteins. In addition, we demonstrated that shRNA-mediated knockdown of Rasd1 results in further repression of Ear2-mediated renin transcription, whereas induction of Rasd1 by dexamethasone counteracts the effects of shRNA-mediated Rasd1 knockdown. Finally, our study showed that Rasd1 missense mutations not only attenuate their physical interaction with Ear2 but also abolish their ability to counteract repression of renin transcription mediated by Ear2.

Conclusions: Our study provides evidence for physical and functional interactions between Rasd1 and Ear2. The results suggest that their interactions are involved in renin transcriptional regulation. These findings not only reveal a novel role for Rasd1-medated signaling but also provide the basis for potential intervention of renin expression.
\end{abstract}

\section{Background}

The renin-angiotensin system plays a major physiological role in the control of blood pressure, fluid volume and electrolyte balance. A functional renin-angiotensin system is also essential for the normal development of the mammalian renal system [1]. Renin, an aspartyl protease, is the rate-limiting enzyme in the renin-angiotensin enzymatic cascade which leads to the production of angiotensin II (Ang II), a vasoactive peptide and major effector molecule in the renin-angiotensin system [2,3]. Renin gene expression is largely regulated at the transcriptional level, although post transcriptional regulation has also been reported $[4,5]$. A potent classical transcriptional

\footnotetext{
* Correspondence: kschen@ntu.edu.sg

'School of Biological Sciences, Department of Genomics and Genetics, Nanyang Technological University, 60 Nanyang Drive, 637551, Singapore Full list of author information is available at the end of the article
}

enhancer was identified $\sim 2.6 \mathrm{~kb}$ upstream of the mouse renin gene, and this enhancer is homologous to a sequence $\sim 12 \mathrm{~kb}$ upstream of the human renin gene [6-8]. The transcriptional enhancer contains several transcription factor binding sites that have both excitatory and inhibitory regulatory functions [9-12].

One protein that has been identified to bind to and regulate the renin enhancer is Ear2 [13]. It was determined that Ear2 negatively regulates renin expression by competing with retinoic acid receptor/ retinoid X receptor (RAR/RXR) for binding to the retinoic acid response elements (RARE) on the renin enhancer [13]. Ear2 is an orphan nuclear hormone receptor that belongs to the chicken ovalbumin upstream promoter-transcription factors (COUP-TF) gene family [14]. COUP-TFs have been shown to bind to a number of variable direct and indirect repeats with different spacings between the
C Biomed Central

C 2011 Tan et al; licensee BioMed Central Ltd. This is an Open Access article distributed under the terms of the Creative Commons Attribution License (http://creativecommons.org/licenses/by/2.0), which permits unrestricted use, distribution, and reproduction in any medium, provided the original work is properly cited. 
repeats [15] to affect a large plethora of genes [16-19]. COUP-TFs have been proposed to inhibit transactivation of other nuclear receptors through multiple mechanisms, including competitively binding to regulatory elements, competitively binding to RXR, mediating active repression via direct binding to regulatory elements, and mediating transrepression of another nuclear receptor without binding to DNA itself [14,20-22]. Nuclear hormone receptors have the ability to bind directly to DNA and regulate the expression of specific target genes; therefore, they are extremely crucial to the development, homeostasis and metabolism of an organism [16,20,21, 23-25]. Ear2 is expressed in tissues of all major systems, and its expression has been implicated in the regulation of gene expression for normal embryo development $[26,27]$. Ear2 knockout mice are viable and fertile, but they possess circadian and nociception defects and abnormal locus coeruleus (LC) development [25].

Using a yeast two-hybrid system, we identified Ear2 as an interacting protein of Rasd1. Rasd1 is a G-protein that belongs to the RAS superfamily of small GTPases. It was first discovered as a dexamethasone-inducible gene in the AtT-20 pituitary cell line [28]. Rasd1 is an oscillating gene specific to the suprachiasmatic nucleus (SCN) [29]. Rasd1 modulates several signaling cascades and has several known functions. It interacts with neuronal nitric oxide synthase via CAPON to enhance physiological nitric oxide signaling [30]. Rasd1 is also crucial in the regulation of the responsiveness of the circadian clock to external stimuli [31]. In this study, we demonstrate that the interaction between Rasd1 and Ear2 regulates renin transcription. Our findings reveal a novel regulatory role of Rasd1 and a novel regulatory mechanism for Ear2-mediated renin transcription.

\section{Results}

Identification of Ear2 as a Rasd1 interacting protein- To identify the proteins that are associated with Rasd1, we conducted a yeast two-hybrid screen. A mouse brain cDNA library was screened against full length Rasd1. All surviving colonies after nutritional selection were screened for $L a c Z$ expression using $\beta$-galactosidase. Table 1 lists the proteins that were identified. Ear2 is the protein for which the highest number of independent clones was obtained, with a total of three clones identified. To confirm the specificity of interaction between Rasd1 and Ear2, a separate yeast two-hybrid analysis was performed by mating yeast containing the Ear2 cDNA plasmid with yeast that already carried Rasd1. This was followed by nutritional selection and $\beta$-galactosidase assay. Ear2 again showed positive interactions with Rasd1 (not shown).

Rasd 1 and Ear2 interact in vitro and in living cellsTo confirm the specificity of biochemical interaction
Table 1 Proteins identified from the yeast two-hybrid screen

\begin{tabular}{llll}
\hline $\begin{array}{l}\text { No } \\
\text { Gene }\end{array}$ & $\begin{array}{l}\text { Protein/ } \\
\text { Gene Name }\end{array}$ & $\begin{array}{l}\text { Genbank } \\
\text { Accession No. }\end{array}$ \\
\hline 2 & Cenpb & Mus musculus centromere protein B & NM_007682.2 \\
\hline 3 & Nr2f6 & $\begin{array}{l}\text { Mus musculus guanine nucleotide } \\
\text { binding protein, beta 1 } \\
\text { subfamily 2, group F, member 6 }\end{array}$ & NM_008142.3 \\
\hline 4 & Plscr1 & $\begin{array}{l}\text { Mus musculus phospholipid } \\
\text { scramblase 1 }\end{array}$ & NM_010150.2 \\
\hline 5 & Sh3gl2 & Mus musculus SH3-domain GRB2-like 2 & NM_019535.2 \\
\hline 6 & Supt16 h & $\begin{array}{l}\text { Mus musculus suppressor of Ty 16 } \\
\text { homolog }\end{array}$ & NM_033618.2 \\
\hline 7 & Trp53bp2 & $\begin{array}{l}\text { Mus musculus transformation related } \\
\text { protein 53 binding protein 2 }\end{array}$ & NM_173378.2 \\
\hline 8 & Ywhah & $\begin{array}{l}\text { Mus musculus tyrosine 3- } \\
\text { monooxygenase/tryptophan 5- } \\
\text { monooxygenase activation protein, eta } \\
\text { polypeptide }\end{array}$ & NM_011738.1 \\
\hline
\end{tabular}

between Rasd1 and Ear2, we conducted an in vitro binding study utilizing transfected COS-7 cells. GST-Ear2 was immobilized on GSH-linked beads. The GST fusion protein containing full-length Ear2 interacted with HAtagged full-length Rasd1 from the lysate of transfected COS-7 cells (Figure 1A, lane 1), whereas GST itself showed no such interaction (Figure 1A, lane 2).

To test whether Rasd1 and Ear2 interact in intact mammalian cells, we performed co-transfection and co-precipitation experiments. pHisHA-Rasd 1 was co-transfected together with pGST-Ear2 into COS-7 cells. As a control, pHisHA-Rasd1 was co-transfected with pxJGST into COS-7 cells. GST-Ear2 or GST from transfected COS-7 cell lysate was immobilized on GSH-linked magnetic particles. Precipitation of GST-Ear2 resulted in the co-precipitation of HisHA-Rasd1 (Figure 1B, lane 1), whereas precipitation of GST-tag alone did not co-precipitate HisHA-Rasd1 (Figure 1B, lane 2). This demonstrates that Rasd1 and Ear2 form a physiological complex in cultured cells. Additionally, a co-immunoprecipitation assay was carried out using lysate derived from COS-7 co-transfected with pHisHA-Rasd1 and pGST-Ear2. As a control, experiments were also conducted using lysate derived from COS-7 cells co-transfected with pHisHA-Rasd1 and pxJGST. Immunoprecipitation of GST-Ear2 with anti-GST antibody resulted in the co-precipitation of HisHA-Rasd1 (Figure 1C, lane 1). There was no non-specific interaction between GST tag and HisHA-Rasd1 (Figure 1C, lane 2).

Interaction of endogenous Rasd1 and Ear2 was identified in HEK293T cells and the mouse brain- The existence of endogenous Rasd1-Ear2 complexes was further 
(A)

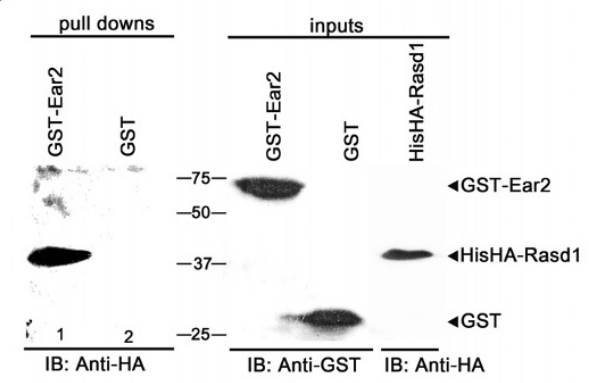

(C)

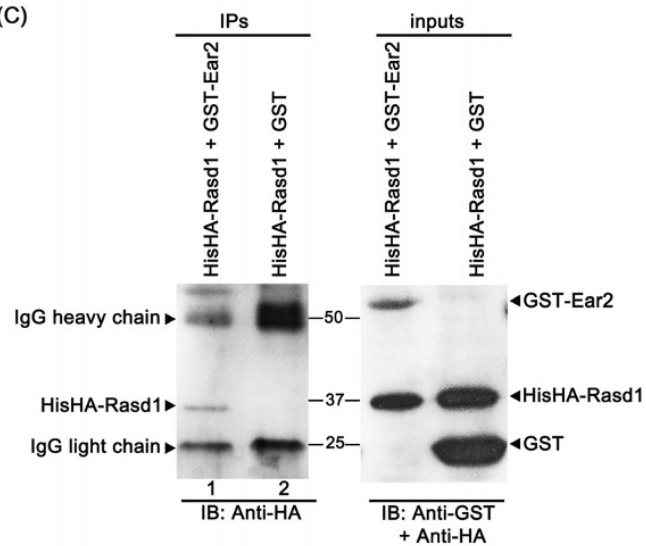

(E)

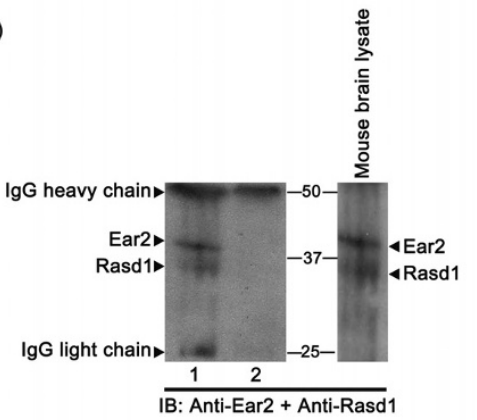

(B)

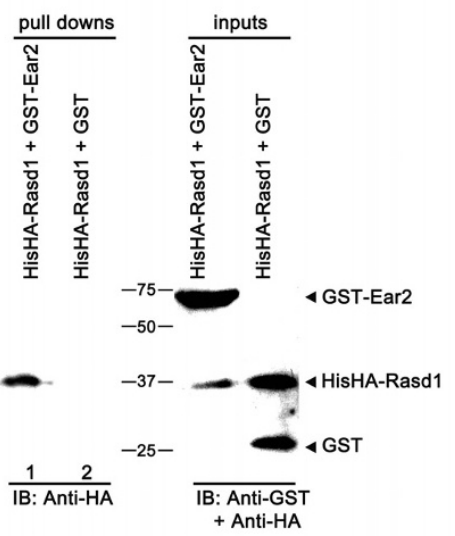

(D)

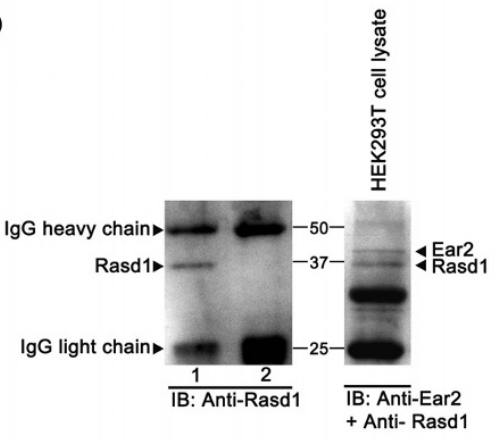

Figure 1 Rasd1 and Ear2 interact in vitro and in living cells. (A) In vitro binding of GST-Ear2 and HisHA-Rasd1. COS-7 cells were transfected with plasmids expressing the indicated constructs. Cell lysates containing HisHA-Rasd1 was incubated with immobilized GST-Ear2 or GST, and specifically bound HisHA-Rasd 1 was eluted by heating at $95^{\circ} \mathrm{C}$ for 10 minutes, and detected by Western blotting with Anti-HA antibody. (B) HisHA-Rasd1 and GST-Ear2 interact in intact mammalian cells. pHisHA-Rasd1 was co-transfected with plasmids expressing either GST-Ear2 or GST into COS-7 cells. GST and GST-Ear2 were captured from the cell lysates by GSH-linked beads and HisHA-Rasd1 bound to the beads were detected as above. (C) COS-7 cells were co-transfected with plasmids expressing HisHA-Rasd1 and GST-Ear2 or GST. Immunoprecipitations were performed with anti-GST antibody. Co-immunoprecipitated HisHA-Rasd1 was detected by Anti-HA antibody. (D and E) Rasd1 and Ear2 form a physiological complex in living cells. Endogenous Rasd1-Ear2 complexes were detected by immunoprecipitating Ear2 from HEK293T cell lysates (D) or mouse brain lysates (E) with goat polyclonal IgG anti-Ear2 antibody, and probing for Rasd1 ( $D$ and E, lanes 1). A non-relevant goat polyclonal IgG antibody was used as a negative control ( $D$ and $E$, lanes 2). IP and IB denote immunoprecipitation and immunoblot, respectively.

demonstrated by co-immunoprecipitation of the protein complex from both HEK293T cells and mouse brain. Immunoprecipitation of endogenous Ear2 resulted in the co-immunoprecipitation of Rasd1 (Figure 1D, lane 1 and Figure 1E, lane 1), but immunoprecipitation performed with a non-relevant goat polyclonal IgG antibody did not co-immunoprecipitate Rasd1 (Figure 1D, lane 2 and Figure 1E, lane 2). These experiments confirm the specificity of the endogenous interaction between Rasd1 and Ear2. 
Rasd1 alleviates Ear2-mediated repression of renin transcription-Ear2 binds to the RARE on the renin enhancer and negatively regulates renin gene transcription [13]. The most important regulatory regions of the mouse renin gene reside in $4.1 \mathrm{~kb}$ of the renin $5^{\prime}$ flanking sequence [6,32]. To explore the possibility that Rasd1 modulates Ear2-mediated transrepression of renin expression, we cloned the $4.1 \mathrm{~kb}$ renin promoter and enhancer into the promoterless, enhancerless luciferase pGL3-Basic vector (p4.1-Luc). COS-7 cells were transfected with pGL3-basic or p4.1-Luc or p4.1-Luc and pGST-Ear2. We first validated that Ear2 acts as a negative regulator on renin gene transcription [13] in COS-7 cells (Figure 2A). We then proceeded to test if Rasd1 was able to modulate renin transcription in the presence of Ear2. Our results show that Rasd1 alleviates the Ear2mediated transcriptional repression of renin promoter activity in a dosage-dependent manner (Figure 2B). It has also been reported that Ear2 is able to downregulate retinoic acid-induced renin transcription [13]. We validated this result (Figure 2C) and tested if Rasd1 was able to alleviate Ear2-mediated transcriptional repression of retinoic acid-induced renin expression. Our results suggest that Rasd1 is able to alleviate Ear2-mediated transcriptional repression of retinoic acid-induced renin promoter activity in a dosage dependent manner (Figure $2 \mathrm{D}$ and $2 \mathrm{E})$.

Rasd1 modulates endogenous renin gene expression by interacting with Ear2- We also investigated the effects of Ear2 and Rasd1 on endogenous renin gene expression in As4.1 cells. As4.1 cells express endogenous renin, as well as Rasd1 and Ear2. Real-time RT-PCR showed that renin mRNA levels were lower in the cells over-expressing Ear2. Renin mRNA in As4.1 cells over-expressing Ear2 were reduced to about $48 \%$ of the control (Figure 3A, compare bars I and II). When pHisHARasd1 was co-transfected with pGST-Ear2 into As4.1 cells, the repression of renin transcription by Ear2 was inhibited (Figure 3A, compare bars II and III). Renin mRNA levels increased to almost twice the amount of control when Rasd1 was over-expressed (Figure 3A, compare bars I and III). This spike in renin gene expression when Rasd1 was over-expressed could be attributed to the presence of abundant Rasd1, which might have counteracted the repression of renin transcription by both endogenous and transfected Ear2.

We proceeded to test if alteration of Rasd1 levels in As4.1 cells is capable of modulating Ear2-mediated repression of renin transcription. As4.1 cells are known to express high level of renin [33]. We first demonstrated that Rasd1 shRNA, but not control shRNA, effectively knocked down endogenous expression of Rasd1 mRNA (Figure 3B, upper panel) and protein (Figure 3B, lower panel) in As4.1 cells. Quantifications with the densitometer indicated that protein levels were knocked down by more than $48 \%$. In addition, we demonstrated that shRNA-mediated knockdown of Rasd1 results in a further repression of Ear2-mediated renin transcription (Figure 3C, compare bars V and VI). Because dexamethasone is known to induce Rasd1 expression [28], we examined whether dexamethasone could counteract the effects of shRNA-mediated Rasd1 knockdown. In the presence of dexamethasone, Ear2repressed renin transcription was alleviated (Figure 3C, compare bars $\mathrm{V}$ and VII). This resembled the results we observed from Rasd1 over-expression (Figure 3C, compare bars III and IV). Treatment with dexamethasone counteracted the effects of Rasd1 shRNA on the Ear2mediated repression of renin transcription (Figure 3C, compare bars VI and VIII); however, renin transcription levels were restored to lower levels than that of treatment with dexamethasone alone (Figure 3C, bar VII). Our experiments suggest that transcriptional repression of renin by Ear2 can be modulated by alternating the level of Rasd1 in As4.1 cells.

Ear2 interacts with Rasd1 via its ligand binding domain- Ear2 is a 390 amino acid nuclear hormone receptor and is known to contain several domains, including an activator function I site (residues 1-53), a DNA-binding domain (residues 54-130), a linker region (residues 131-193) and a ligand binding domain (residues 194-376). To elucidate how Rasd1 interacts with Ear2, we generated six GST-Ear2 truncated constructs (Figure 4A) and used them to carry out co-precipitation assays against full-length HisHA-Rasd1. We found that only full-length Ear2 (Figure 4A, Ear2-FL) and Ear2 truncated constructs that contain the ligand binding domain (Figure 4A, Ear2-C54, Ear2-C131 and Ear2C194) co-precipitated with HisHA-Rasd1 (Figure 4B, lane 1 and lanes 5-7). This indicates that the C-terminus ligand binding domain, containing amino acids 194-390, is required for the binding of Ear2 to Rasd1.

Ear2 ligand binding domain is required for Rasd1 to alleviate Ear2-mediated repression of renin transcription- To further investigate the binding of Ear2 on the renin enhancer [13], we performed luciferase assay using the six truncated constructs of Ear2. Ear2 deletion constructs devoid of the DNA binding domain markedly lost their ability to repress renin transcription (Figure 4C, bars with Ear2-N53, Ear2-C131 and Ear2-C194). This result is in accordance with previous report which shows that Ear2 with a mutated DNA binding domain is unable to bind to the RARE and ineffective in inhibiting the activity of the renin promoter [13].

When Rasd1 was added, we observed that Rasd1 alleviated Ear2-mediated transcriptional repression of renin promoter activity only in Ear2 constructs with intact DNA and ligand binding domains (Figure 4C, bars with 
(A)

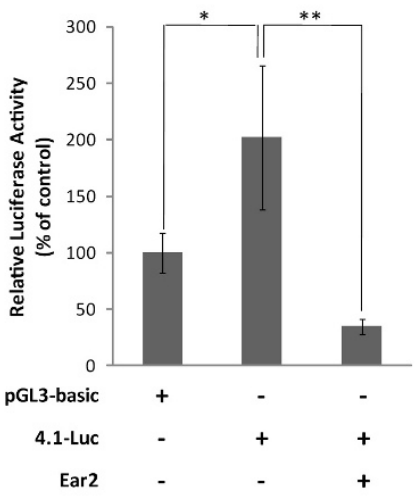

(C)

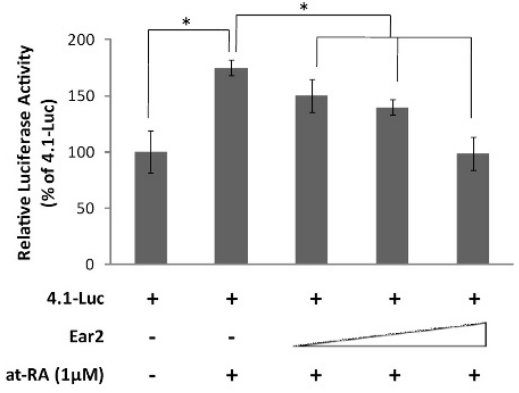

(B)

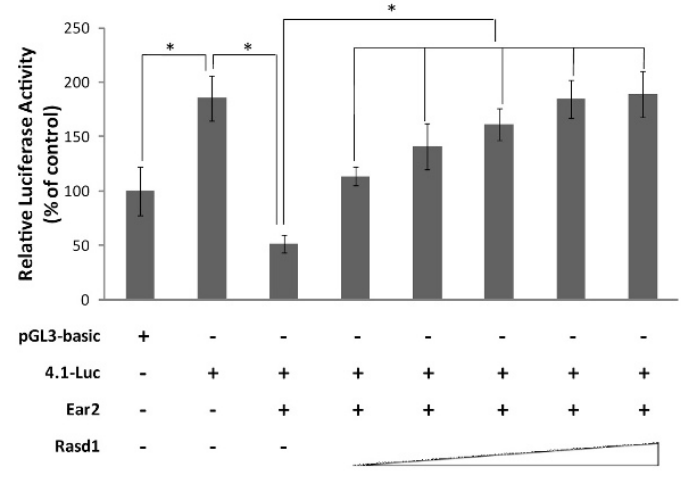

(E)

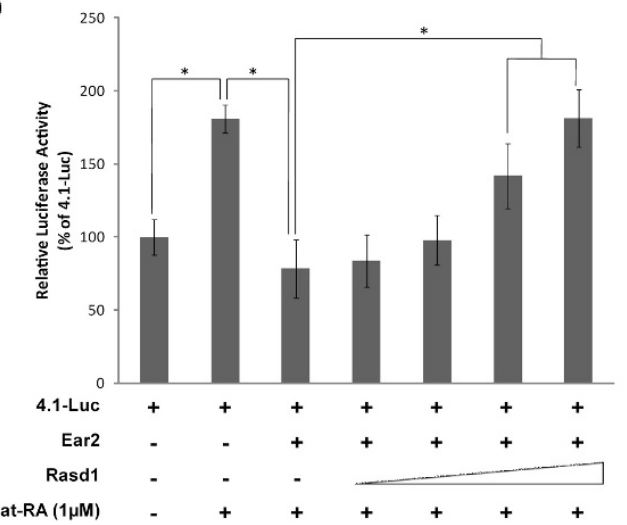

Figure 2 Rasd 1 counteracts repression of renin transcription by Ear2. (A) Luciferase assay showed that transcription of renin is repressed by Ear2. COS-7 cells were transfected with pGL3-basic $(2.0 \mu \mathrm{g})$ or p4.1-Luc $(2.0 \mu \mathrm{g})$ or p4.1-Luc $(2.0 \mu \mathrm{g})$ and pGST-Ear2 $(1.5 \mu \mathrm{g})$, and with pSV- $\beta$-gal $(0.5 \mathrm{\mu g})$. p4.1-Luc construct was generated by cloning the $4.1 \mathrm{~kb}$ renin promoter into pGL3-basic vector. Relative luciferase activity was normalized against $\beta$-gal activity. (B) Rasd1 alleviates Ear2-mediated repression of renin transcription in a dosage dependent manner. COS-7 cells were transfected with a constant amount of p4.1-Luc $(2.0 \mu \mathrm{g})$, pSV- $\beta$-gal $(0.5 \mu \mathrm{g})$ and pGST-Ear2 $(1.5 \mu \mathrm{g})$, and with an increasing amount of pHisHA-Rasd1 (0.1, 0.2, 0.5, 1.0 and $1.5 \mu \mathrm{g}$ ). (C) Ear2 attenuates the renin promoter activity induced by retinoic acid in a dosage dependent manner. COS-7 cells were transfected with a constant amount of p4.1-Luc $(2.0 \mu \mathrm{g})$, pSV- $\beta$-gal $(0.5 \mu \mathrm{g})$ and pHisHA-Rasd1 $(1.5 \mu \mathrm{g})$, and with an increasing amount of pGST-Ear2 $(0.5,1.0$ and $1.5 \mu \mathrm{g})$. Renin transcription was induced by all-trans retinoic acid 24 hours post transfection. (D and E) Rasd1 alleviates Ear2-mediated repression of retinoic acid induced renin transcription in a dosage dependent manner. The effect of Rasd1 and Ear2 on retinoic induced renin transcription was tested by measuring the luciferase activity in varying amounts of either Ear2 (D) or Rasd1 (E). The amounts of pGST-Ear2 transfected in $D$ were $0.5,1.0$ and $1.5 \mu \mathrm{g}$; the amounts of pHisHA-Rasd1 transfected in $E$ were $0.2,0.5,1.0$ and $2.0 \mu \mathrm{g}$. ${ }^{*}$ and ${ }^{* *}$ denotes $p<0.05$ and $p<0.01$ respectively. (A-E) In all luciferase assays, controls were transfected with pGL3-basic $(2.0 \mu g)$, pSV- $\beta$-gal $(0.5 \mu \mathrm{g})$ and appropriate amounts of the respective carrier vectors. 
(A)
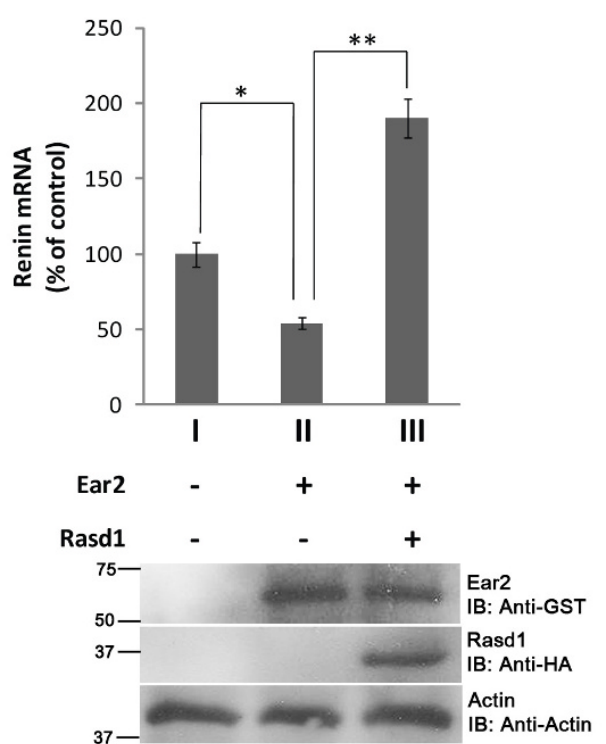

(B)

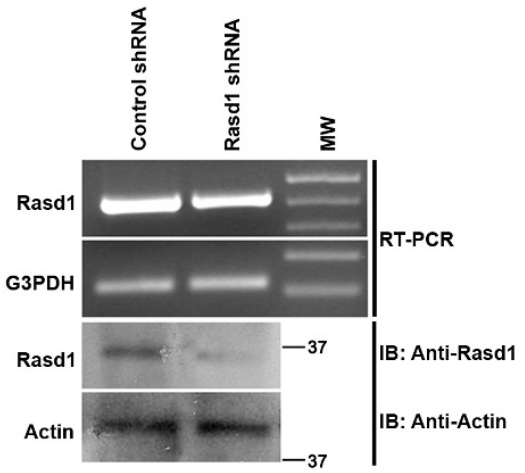

(C)

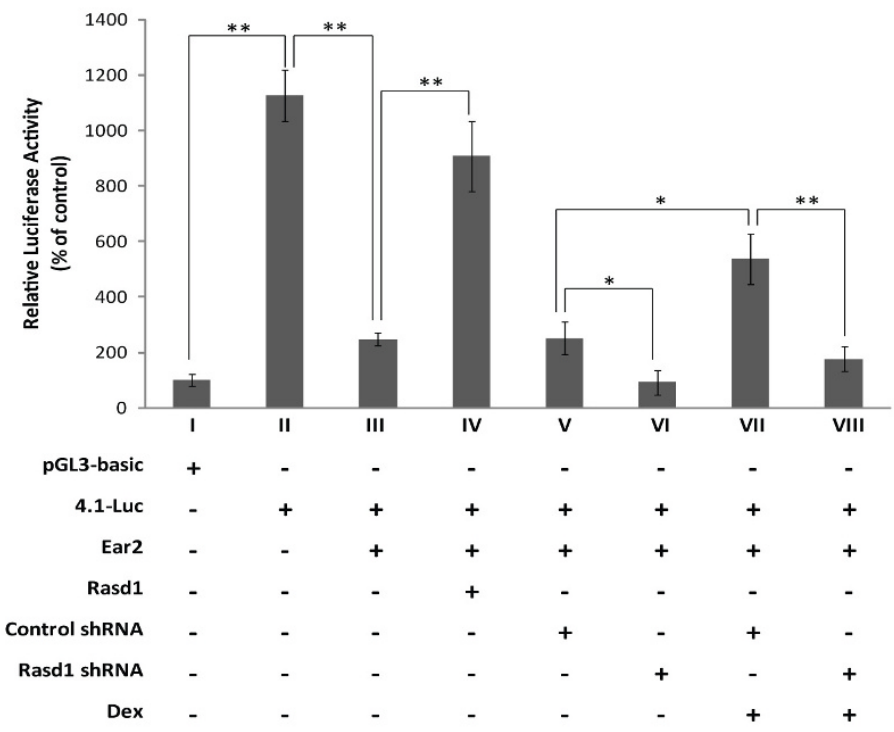

Figure 3 Transcriptional repression of renin by Ear2 can be modulated by alternating the endogenous level of Rasd1. (A) Real-time RT-PCR was conducted to determine level of endogenous renin transcription when Rasd1 was overexpressed. As4.1 cells were transiently transfected with pxJGST $(2.0 \mu \mathrm{g})$ and pcDNA4.0 $(3.5 \mu \mathrm{g})($ bar I), or pGST-Ear2 $(2.0 \mu \mathrm{g})$ and pcDNA4.0 $(3.5 \mu \mathrm{g})($ bar II), or pHisHA-Rasd1 $(3.5 \mu \mathrm{g})$ and pcDNA4.0 $(3.5 \mu \mathrm{g})$ (bar III). Representative immunoblots demonstrated Ear2 and Rasd1 transgene expression 48 hours after transfection (lower panels). (B) Semi-quantitative RT-PCR showed Rasd1 knockdown in the As4.1 cells. As4.1 cells were transfected with Rasd1 shRNA or control shRNA $(4.0 \mu \mathrm{g})$. Cells were selected with puromycin 24 hours post transfection and harvested 48 hours post transfection. The cDNA amplified were run on a 1.5\% agarose gel with G3PDH as an internal control (upper panels). A representative immunoblot demonstrated endogenous Rasd1 protein knockdown by Rasd1 shRNA (lower panel). Proteins were detected with anti-Rasd1 and anti-actin antibodies. Quantification of the immunoblots by densitometer revealed that Rasd1 protein levels, normalized against actin protein levels, were knocked down by more than $48 \%$ (lower panels). (C) Luciferase study showed that dexamethasone treatment counteracts the effect of Rasd1 shRNA knockdown. As4.1 cells were transfected with p4.1-Luc $(2.0 \mu \mathrm{g})$, pGST-Ear2 $(1.5 \mu \mathrm{g})$, pHisHA-Rasd1 $(1.5 \mu \mathrm{g})$, Rasd1 shRNA or control shRNA as indicated $(4.0 \mu \mathrm{g})$, together with pSV- $\beta$-gal $(0.5 \mu \mathrm{g})$. Controls were transfected with pGL3-basic $(2.0 \mu \mathrm{g})$, pSV- $\beta$-gal $(0.5 \mu \mathrm{g})$ and appropriate amounts of the respective carrier vectors. Cell were selected with puromycin $(2 \mu \mathrm{g} / \mathrm{ml})$ and induced by dexamethasone $(100 \mathrm{nM}) 24$ hours after transfection. Cells were harvested and analyzed for luciferase activity 48 hours after transfection. Relative luciferase activity was normalized against $\beta$-gal activity. ${ }^{*}$ and ${ }^{* *}$ denotes $p<0.05$ and $p<0.01$, respectively. 
(A)
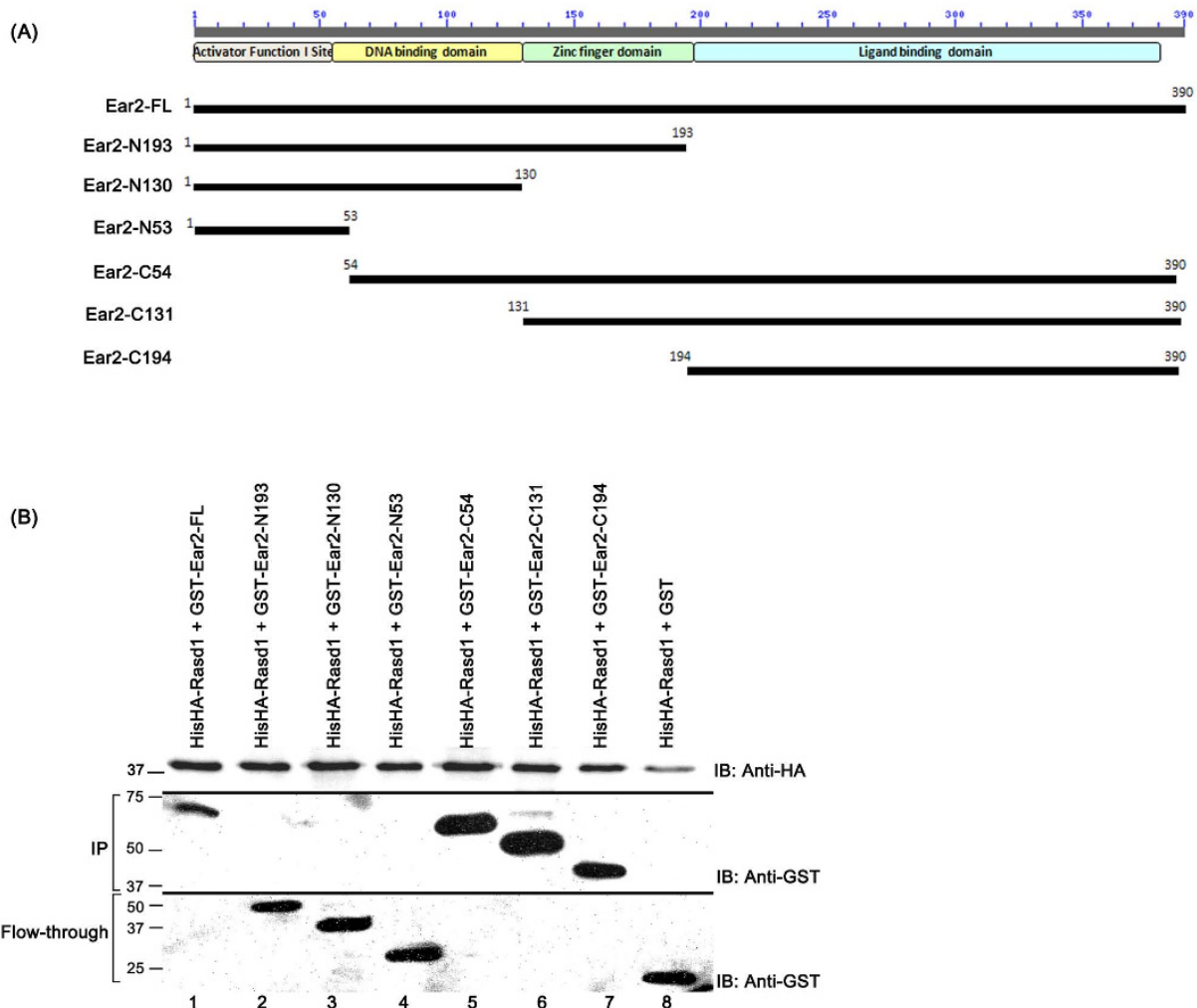

(C)

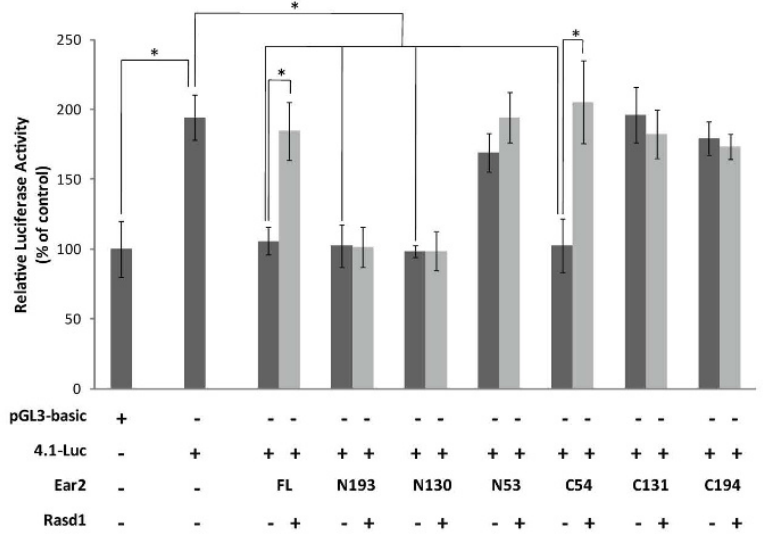

Figure 4 Ear2 ligand binding domain interacts with Rasd1. (A) Schematic diagram showing the truncated constructs of Ear2. Ear2 contains 4 main domains: an activator function I site, a DNA binding domain, a zinc finger domain and a ligand binding domain. Full length (FL) Ear2 has 390 amino acids and each of the six truncated Ear2 constructs is represented by their amino acid numbers on the left. (B) Immunoblot analysis showed that Rasd1 binds to Ear2 ligand binding domain. COS-7 cells were co-transfected with pHisHA-Rasd1 and the indicated pGST-Ear2 constructs. HisHARasd 1 from the cell lysates was immobilized on Ni-NTA beads and GST-Ear2 constructs bound to the complexes were eluted by heating at $95^{\circ} \mathrm{C}$ for 10 minutes, and detected by immunoblotting with anti-GST (lanes 1 and 5-7). GST-Ear2 constructs not co-precipitated with HisHA-Rasd1 were detected in the flow-through (lanes 2-4 and 8). (C) Luciferase study showed that Ear2 ligand binding domain and DNA binding domain are required for interacting with Rasd1 to modulate renin transcription. COS-7 cells were transfected with p4.1-Luc $(2.0 \mu \mathrm{g})$, pGST-Ear2 $(1.5 \mu \mathrm{g})$ or plasmids expressing Ear2 truncated constructs and pHisHA-Rasd1 $(1.5 \mu \mathrm{g})$ as indicated, together with pSV- $\beta$-gal $(0.5 \mu \mathrm{g})$. Total DNA transfected was held constant with the respective carrier vector plasmids. Controls are transfected with pGL3-basic $(2.0 \mu \mathrm{g}), \mathrm{pSV}-\beta$-gal $(0.5 \mu \mathrm{g})$ and appropriate amounts of the respective carrier vectors. Relative luciferase activity was normalized against $\beta$-gal activity. Ear2 constructs that were missing their DNA binding domains (Ear2N53, Ear2-C131, Ear2-C194) did not significantly repress renin transcription. Rasd1 alleviated Ear2-repressed renin transcription only if Ear2 ligand binding domain is present (Ear2-FL, Ear2-C54). * denotes $p<0.05$. 
Ear2-FL and Ear2-C54). This further confirms our previous observations that Rasd1 interacts with the ligand binding domain of Ear2. It also shows that the specific binding of Rasd1 to Ear2 is essential for Rasd1 to counteract Ear2-mediated transrepression of renin promoter. In addition, it was observed that the activator function I domain (Figure 4A, Ear2-N53) of Ear2 was not required for its repression of renin promoter activity. Deletion of the activator function I domain has no influence on either the Ear2-mediated repression or the Rasd1-mediated alleviation of renin promoter activity (Figure 4C, lanes with Ear2-FL and Ear2-C54).

Rasd1 and Ear2 colocalize in the nuclei - Rasd1 and Ear2 must both be physically present in the same cellular compartment to form a physiological complex. We therefore decided to examine the localization of Rasd 1 and Ear2 in transfected COS-7 cells. When transfected alone, HisHA-Rasd1 was expressed in both the cytoplasm and the nucleus (Figure 5, A1-3), while GST-Ear2 was present mainly in the nucleus (Figure 5, B1-3). When GST-Ear2 and HisHA-Rasd1 were coexpressed, it was observed that HisHA-Rasd1 and GST-Ear2 colocalized in both the cytoplasm and the nucleus (Figure 5, C1-4). It is interesting to note that the amount of GST-Ear2 present in the cytoplasm was dramatically increased in the presence of HisHA-Rasd1 (compare Figure 5, B1 with C2); there was no noticeable change in the distribution of HisHA-Rasd1 in the presence or absence of GST-Ear2 (compare Figure 5, A1 with C1).

Missense mutations in Rasd1 abolished its physical and functional interaction with Ear2- Rasd1 is a brainenriched G protein that belongs to the RAS superfamily [34]. RAS superfamily members consists of GTPases with high conservation in sequence and structural organization, especially within their GTP binding pockets -G1, G3, G4 and G5 boxes [34]. Most RAS subfamily proteins also possess a C-terminus CAAX box, which undergoes post-translational isoprenylation and regulates the subcellular localization and function of the proteins [35]. To investigate whether GTPase activity, GDP-GTP exchange by GEF and post-translational isoprenylation of Rasd1 are required for its alleviation of Ear2-mediated repression of renin transcription, we generated four Rasd1 mutants- Rasd1[A178V], Rasd1[G81A], Rasd1[T38N] and Rasd1[ $\triangle \mathrm{CAAX}$. Rasd1[A178V] [36] contains a single nucleotide mutation in the G5 domain, disrupting its guanyl nucleotide binding pocket. Rasd1 [A178V] behaves functionally as a constitutively active signal transducer. Rasd1[G81A] possesses a point mutation that lies on a highly conserved glycine residue in the G3 box [37]. In human HRAS, the corresponding G60A mutation drastically reduces its GTPase activity [38]. Rasd1[T38N] contains a mutation in the G1 box, corresponding to human RAS[S17N]. Human HRAS[S17N] binds guanine nucleotide exchange factors (GEFs) but does not catalyze the release of GDP, thus effectively blocking the activation of RAS $[39,40]$. To explore the potential role of isoprenylation in the functional properties of Rasd1, we generated Rasd1[ $\triangle \mathrm{CAAX}]$. This mutant contains a premature termination codon that gives rise to a truncated Rasd1 devoid of the CAAX box.

The Rasd1 mutant constructs were co-transfected with Ear2 and their cellular localization was examined. Rasd1 [A178V] and Rasd1[T38N] exhibited a similar distribution to that of wild type Rasd1 and were present in both the nucleus and cytoplasm (Figure 5, A1, D1 and F1). Rasd1[G81A] and Rasd1[ $\triangle \mathrm{CAAX}]$ were located only in the nucleus (Figure 5, E1 and G1). When co-expressed with Ear2, the amount of Ear2 present in the cytoplasm was visibly increased in the presence of Rasd1[A178V] (compare Figure 5, B1 and D2). On the other hand, $\operatorname{Rasd1}[\mathrm{G} 81 \mathrm{~A}], \operatorname{Rasd} 1$ [T38N] and Rasd1[ $\triangle \mathrm{CAAX}]$ did not alter the distribution of Ear2. Ear2 was still mostly located in the nucleus in the presence of these Rasd1 mutants (Figure 5, E2, F2, and G2).

We proceeded to perform luciferase assays to investigate the effect of the expression of wild-type versus various mutant Rasd1 proteins on Ear2-mediated renin promoter activity in three cell lines, including COS-7 (monkey kidney fibroblast cell line), As 4.1 (mouse juxtaglomerular cell line) and Neuro2a (mouse neuroblastoma cell line). Both As4.1 and Neuro2a cells are known to endogenously express renin $[33,41]$, whereas no endogenous expression of renin is observed in COS-7cells [12]. In agreement with this, the 4.1-Luc reporter construct exhibited an eleven fold and four fold higher luciferase reporter activity in As4.1 and Neuro2a cells, respectively, than in COS-7 cells (compare Figure 6 bars: BII and AII; CII and AII). Luciferase reporter assay showed that over-expression of Ear2 suppressed renin promoter activity in all three cell lines (compare Figure 6 bars: AII and AIII; BII and BIII; CII and CIII) and over-expression of Rasd1 alleviated Ear2mediated down regulation of the renin promoter (compare Figure 6 bars: AIII and AIV; BIII and BIV; CIII and CIV). Likewise, Rasd1[A178V], a constitutively active mutant, alleviated Ear2-mediated down-regulation of the renin promoter in a magnitude similar to that of wild-type Rasd1 (Figure 6A, compare bars: AIII and AIV; BIII and BIV; CIII and CIV). In contrast, Rasd1[G81A], Rasd1 $[\mathrm{T} 38 \mathrm{~N}]$ and Rasd1 $[\triangle \mathrm{CAAX}]$ did not significantly alleviate Ear2-mediated down-regulation of renin transcription (Figure 6A, compare bars III, IV and VI-VIII), thus indicating that the GTP hydrolysis activity of Rasd1, GDPGTP exchange by GEF and isoprenylation of Rasd1 are required for counteracting Ear2-mediated repression of renin transcription. To investigate whether Rasd1[A178V], $\operatorname{Rasd} 1[\mathrm{G} 81 \mathrm{~A}], \quad \operatorname{Rasd} 1[\mathrm{~T} 38 \mathrm{~N}]$ and $\operatorname{Rasd} 1[\triangle \mathrm{CAAX}]$ 
(A-G)

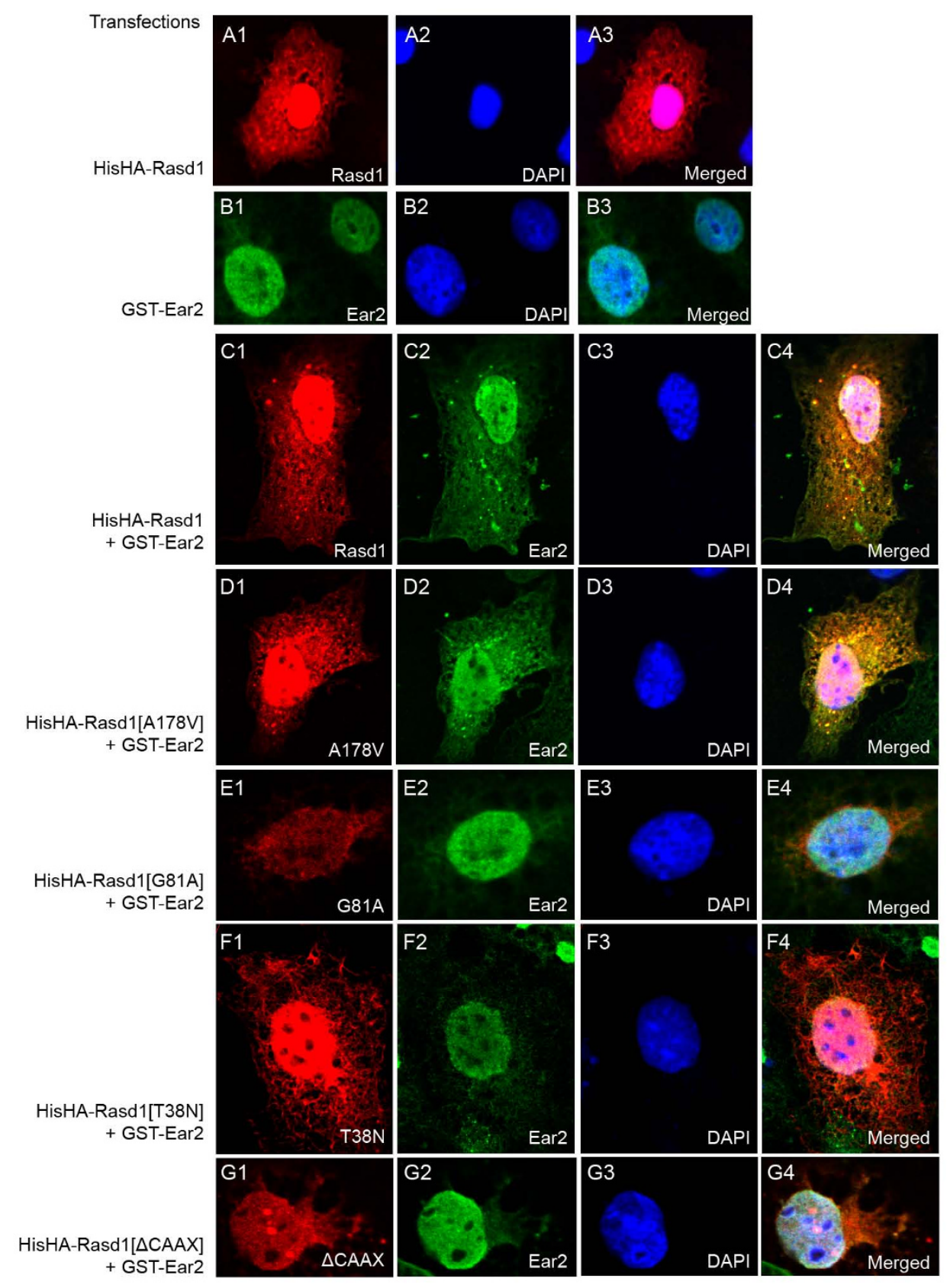

Figure 5 Effects of wild-type and Rasd1 mutants on nuclear-cytoplasmic distribution of Ear2. (A-G) Immunofluorescence staining of COS7 cells transfected with pHisHA-Rasd1 (A1-3) or pGST-Ear2 (B1-3) or pHisHA-Rasd1 (wild type or mutants) + pGST-Ear2 (C1 to G4). HisHARasd1 (wild type or mutants) were detected with anti-HA antibody and visualized with AlexaFluor 568 (red); GST-Ear2 was labeled with anti-GST AlexaFluor 488 (green); nucleus was labeled with 4',6-diamidino-2-phenylindole (DAPI) (blue). Confocal imaging showed that HisHA-Rasd1 is present in both the nucleus and cytoplasm (A1-3). GST-Ear2 is located mainly in the nucleus (B1-3), but when co-transfected together with HisHA-Rasd1, GST-Ear2 is detected in both the nucleus and cytoplasm (C2). 
(A)
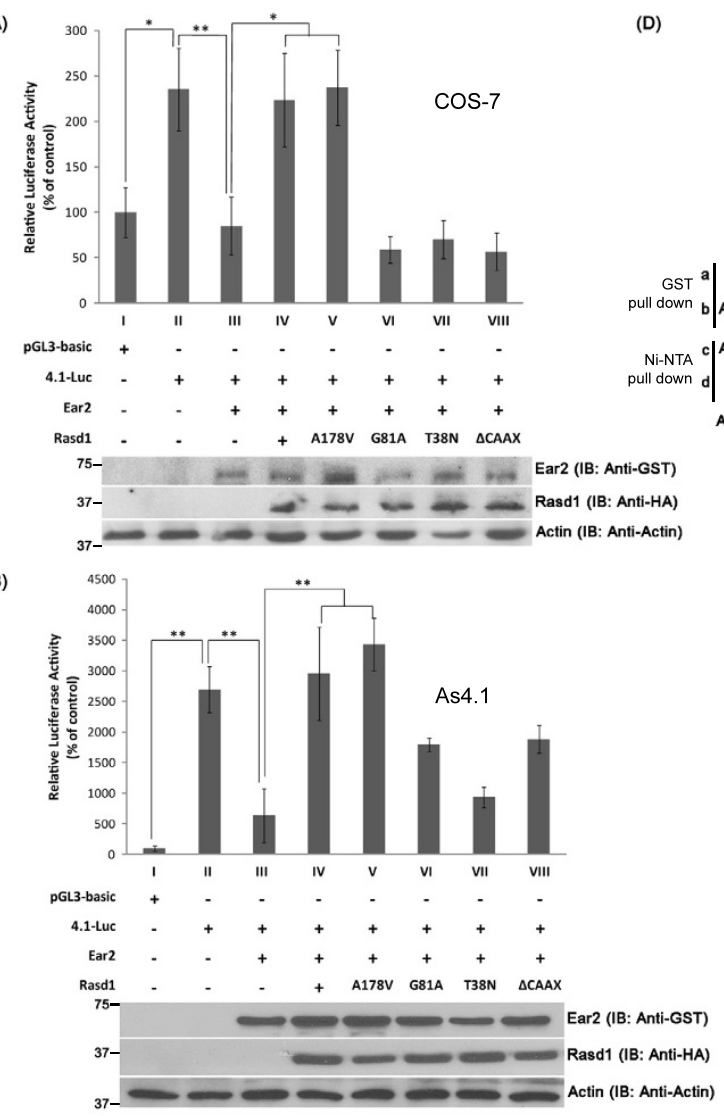

(C)

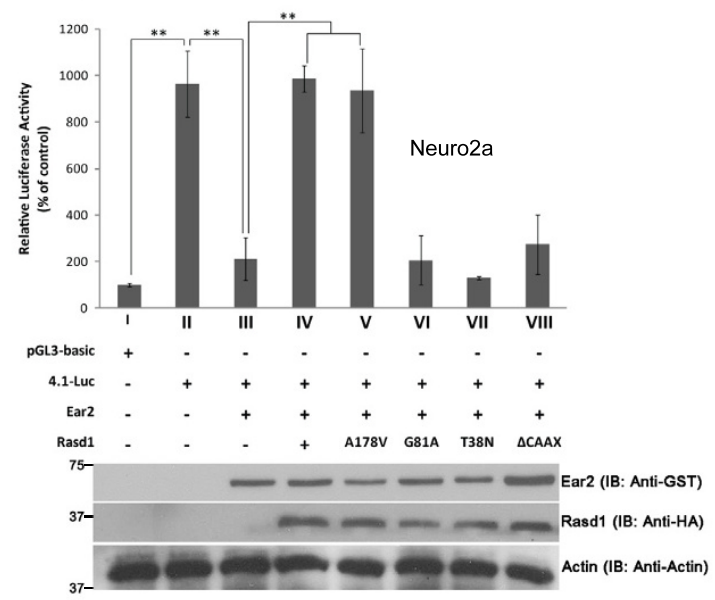

Figure 6 (A-C) Effects of wild-type and Rasd1 mutants on Ear2-mediated renin transcription. Luciferase studies showed that: A, COS-7; B, As4.1; C, Neuro2a. Rasd1[A178V] mutant alleviated Ear2-mediated repression of renin transcription in a magnitude similar to wild-type Rasd1 (compare bars IV and V), whereas Rasd1[G81A], Rasd1[T38N] and Rasd1 [ $\triangle \mathrm{CAAX}$ ] did not significantly alleviate Ear2-mediated repression of renin transcription (bars VI-VIII). (A, B and C, lower panels) Western blots showed similar expression efficiency of proteins. In all blots, expression of actin is shown as a protein loading control. * and ** denotes $p<0.05$ and $p<0.01$, respectively. (D) Co-precipitation followed by immunoblot

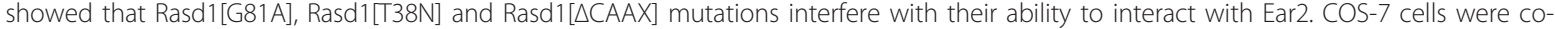
transfected with pGST-Ear2 and the respective Rasd1 construct expressing plasmids or the empty vector. Precipitation of GST-Ear2 with GSHlinked magnetic beads co-precipitated with Rasd1 proteins expressed from each construct (panel a, lanes I-V). However, the amount of HAHisRasd1[G81A], HAHis-Rasd1[T38N] and HAHisRasd1[ $\triangle \mathrm{CAAX}$ ] co-precipitated were significantly less than that of HAHis-Rasd1 and HAHis-Rasd1 [A178V] (compare panel a, lanes I and II with lanes III-V). Similarly, co-precipitation assays using magnetic Ni-NTA beads revealed that the amount of GST-Ear2 co-precipitated with HAHis-Rasd1[G81A], HAHis-Rasd1[T38N] and HAHisRasd1 [ $\triangle \mathrm{CAAX}$ ] were significantly less than that of HAHis-Rasd1 and HAHis-Rasd1[A178V] (compare panel C, lanes I and II with lanes III-V). 
mutations will interfere with their ability to interact with Ear2, we conducted co-immunoprecipitation analyses. The immunoblotting results showed that significantly less $\operatorname{Rasd1}[\mathrm{G} 81 \mathrm{~A}], \operatorname{Rasd} 1[\mathrm{~T} 38 \mathrm{~N}]$ and $\operatorname{Rasd} 1[\Delta \mathrm{CAAX}]$ were co-precipitated with immobilized GST-Ear2 when compared to wild type Rasd1 and Rasd1[A178V] (compare Figure 6D, panel a, lanes I and II with lanes III-V). Similarly, noticeably less GST-Ear2 co-precipitated with immobilized Rasd1[G81A], Rasd1[T38N] and Rasd1 [ $\triangle \mathrm{CAAX}]$ compared to immobilized wild type Rasd1 and Rasd1[A178V] (compare Figure 6D, panel c, lanes I and II with lanes III-V). These results suggest that mutation of amino acid 81, 38 and deletion of the CAAX box of Rasd1 affects the ability of Rasd1to interact with Ear2.

\section{Discussion}

In our present study, we identified Ear2 as a direct interacting target of Rasd1. The interaction between Ear2 and Rasd1 was confirmed in vitro and in living cells. Ear 2 interacts with Rasd 1 via its ligand binding domain. In addition, we demonstrated that Rasd 1 is able to alleviate both retinoic acid-dependent and independent Ear2-mediated transcriptional repression of renin promoter activity. Furthermore, we showed that the Rasd1 mutants, Rasd1[G81A], Rasd1[T38N] and Rasd1 $[\triangle \mathrm{CAAX}]$, which have reduced physical interaction with Ear2, are ineffective in counteracting repression of renin transcription by Ear2. Our current data suggests that Rasd1 may facilitate the translocation of Ear2 from the nucleus to the cytoplasm. Alternatively, Rasd1 may bind to Ear2 and render it inactive in the transrepression of renin promoter. Further experiments are required to delineate the detailed mechanism by which Rasd1 counteracts repression of renin transcription by Ear2.

Ear2 is involved in the negative regulation of renin gene transcription [13]. Renin is the rate-limiting enzyme in the renin-angiotensin enzymatic cascade which leads to the production of the bioactive product Angiotensin-II [2,3]. However, despite the efforts aimed at characterizing the renin enhancer, its functional relevance in vivo has yet to be determined. In our study, we showed that Rasd1 interacts with Ear2, and this finding prompted us further to investigate the role of Rasd1 on Ear2-mediated renin transcription. Interestingly, we found that Rasd1 alleviated Ear2-repressed renin transcription in a dosage-dependent manner and that this novel function of Rasd1 required a specific interaction between Rasd 1 and the ligand binding domain of Ear2.

The renin transcriptional enhancer contains both positive and negative regulatory elements [9-12]. Among them is an unusual RARE with TGACC tandem repeats separated by 10 nucleotides (TGACCT-DR10-TGACCT), which is required for both retinoic acid-mediated and retinoic acid-independent activity of the enhancer [9].
Ear2 has been shown to mediate negative regulation of renin transcription by competing with RAR/RXR for its binding to RARE $[9,13]$. Our experiments showed that Rasd1 is able to relieve Ear2-mediated transcriptional repression of renin via direct interaction with Ear2 both in the presence or absence of retinoic acid. It is possible that Rasd 1 acts by binding directly to Ear2, sequestering Ear2 from the nucleus to the cytoplasm, and removing the inhibitory effect of Ear2 by allowing other stimulatory factors to bind to the renin enhancer. Rasd1 contains a bipartite nuclear localization [36], and has been shown to be present in both nucleus and cytosol [36]. Our immunofluorescence and confocal studies showed that a significant amount of Rasd1 is localized in the nuclei. Interestingly, when Rasd1 was co-transfected with Ear2, it resulted in the movement of a significant amount of Ear2 from the nucleus into the cytosol. This suggests that Rasd1 may play a role in regulating Ear2 nucleus-cytosol distribution.

Rasd1 belongs to the RAS superfamily. Members of the RAS superfamily are highly conserved in sequence and show high degrees of homology across species. Similar to other members of the RAS superfamily, Rasd1 possesses five highly conserved motifs for GTP binding and hydrolysis (G1-G5), an effector loop that mediates protein-protein interactions, and a C-terminus CAAX box that serves as a consensus site for the isoprenylation required for membrane localization [34]. Despite extensive similarities to members of the Ras family, Rasd1 also possesses several differences, including an extended carboxyl terminus variable cationic domain and a high basic net isoelectric point [42]. These differences indicate that Rasd1 may play diverse biological roles that have yet to be discovered. This study demonstrates that Rasd1 serves a novel role in the regulation of Ear2-mediated renin transcription. In view of the highly conserved sequence and function of members of the RAS superfamily, we generated several Rasd1 mutants in an attempt to elucidate the molecular basis of the alleviation of Ear2-mediated repression of renin transcription by Rasd1. As expected, Rasd1[A178V], a constitutively active mutant of Rasd1, was able to alleviate Ear2-mediated transcriptional repression of renin promoter activity. In contrast, Rasd1[G81A], Rasd1 [T38N] and Rasd1[ $\triangle \mathrm{CAAX}]$ did not alleviate Ear2mediated repression of renin transcription. This suggests that GTPase activity, GDP-GTP exchange by GEFs, isoprenylation and possibly, the targeting of Rasd1 to the cell membrane are all involved in this function. Mutant H-RAS[S17N] inhibits Ras dependent pathways and has been shown to have a much higher affinity for GDP than GTP [40]. As expected, the corresponding Rasd1 [T38N] mutant was inactive with respect to the upregulation of renin transcription. Similarly, the CAAX 
box-deficient mutant, Rasd1 $[\triangle \mathrm{CAAX}$, was unable to upregulate renin transcription, thus suggesting that isoprenylation and membrane colocalization of Rasd1 is necessary. Likewise, mutant Rasd1[G81A], which binds with reduced affinity to GAPs and possesses attenuated GTPase activity [38], did not alleviate Ear2-mediated repression of renin transcription. We propose a few plausible explanations for this observation. The binding of Rasd1 to Ear2 and the subsequent translocation and retention of Ear2 in the cytosol by Rasd1 may require the GTP hydrolysis activity of Rasd1. Thus, Rasd1 [G81A], with reduced GTPase activity, does not effectively bind to Ear2 and translocate it out of the nucleus to remove the repression of Ear2 on the renin promoter. Alternatively, the lack of functional activity of Rasd1 [G81A] may be due to a reduced affinity of Rasd1 [G81A] for Ear2. In H-RAS, the G60A mutation perturbs GTP-induced conformational change and abolishes biological activity [43]. In another example, a corresponding mutant of EF-Tu, EF-Tu[G83A], has increased GTPase activity and a reduced binding affinity for aa-tRNA [44].

When we conducted interaction studies, it was discovered that Rasd1[G81A], Rasd1[T38N], Rasd1[ $\triangle \mathrm{CAAX}]$ had visibly weaker interactions with Ear2 compared to wild type Rasd1 and Rasd1[A178V]. Immunofluorescence and confocal studies further show that Rasd1 [G81A], Rasd1[T38N] and Rasd1[ $\triangle \mathrm{CAAX}]$ were ineffective in translocating and retaining Ear2 in the cytoplasm. It is also interesting to note that while wild type Rasd1, Rasd1[A178V] and Rasd1[T38N] were present in both the nucleus and cytoplasm, Rasd1[G81A] and Rasd1 $[\triangle \mathrm{CAAX}]$ were localized mainly in the nucleus, suggesting that GTPase activity and isoprenylation of Rasd1 affects Rasd1 nuclear-cytoplasmic distribution. Taken together, our data implies that GTPase activity, GDPGTP exchange and isoprenylation and membrane localization of Rasd1 is required for its functional activity in the mediation of Ear2-repressed renin transcription. Rasd1 mutants that possess these defects were rendered ineffective in the alleviation of Ear2-repressed renin transcription, possibly due to a weakened interaction with Ear2 and/or a reduced effectiveness in the translocation of Ear2 from the nucleus to the cytoplasm.

Many physiological functions, such as blood pressure, exhibit endogenous rhythmic variability corresponding to a day-night cycle of close to 24 hours and driven by the circadian system, which consists of central oscillators in the SCN and peripheral oscillators in organs like the heart, pancreas, kidneys and liver [45-47]. The expression of Rasd1 in the SCN exhibits a circadian rhythm [29]. This leads us to speculate about the relevance of Rasd1's involvement in the regulation of Ear2mediated renin transcription. We postulate that Rasd1 might be a player in the regulation of the daily circadian pattern of blood pressure through its interaction with Ear2 and consequent effect on renin transcription. Interestingly, Ear2 $2^{-/-}$mice displayed reduced efficiency to photic and feeding time cues entrainment [25]. Ear2 is also required for the normal rhythmic expression of Per1 in the forebrain [25,48]. Might Rasd1 and Ear2, together with other clock genes, work in a currently unknown, complex interacting cascade to affect the circadian control of the renin-angiotensin pathway?

There is substantial evidence supporting the existence of a complete and functionally competent renin-angiotensin system in the brain [3,49-51]. In addition to the classical roles of peripheral angiotensins, various studies have shown that central angiotensins are also involved in less conventional functions, such as sexual behavior [52,53], stress [54-56], and learning and memory [52]. There are also studies that show that the renin-angiotensin system is involved in neurological disorders, including Alzheimer's [57-60] and Parkinson's [60,61] disease. Our identification of this novel regulatory mechanism of the renin-angiotensin system opens exciting possibilities for future research and will be of considerable interest for clinical application. The reninangiotensin system, classically known for its involvement in the regulation of blood pressure, has been a target in the development of drugs for the treatment of hypertension. Hypertension is in turn a potent risk factor for cardiovascular diseases, such as stroke, atherosclerosis, and heart attacks [62-64]. Clinically, inhibitors of the reninangiotensin system are observed to be effective antihypertensive treatments [65-67]. Targeting the brain renin-angiotensin system may also be a viable option for the treatment of mood disorders, cognitive dysfunctions and even neurodegenerative diseases. Obtaining a better understanding of the regulation of the renin-angiotensin system may eventually lead to the production of more effective drugs.

\section{Conclusions}

We conclude that Rasd1 and Ear2 interact physically and functionally. This interaction counteracts the repression of renin transcription by Ear2. Since Ear2 is also known to play an important role in brain development and circadian control, it remains to be determined how the interplay between these two proteins regulates spatial-temporal developmental and physiological processes. The results of this study could provide mechanistic insights into Rasd1's ability to modulate these processes through its interaction with Ear2.

\section{Methods}

Yeast two-hybrid screening- All vectors, yeast strains, reagents and methods were derived from the 
MATCHMAKER Two-Hybrid System 3 (Clontech, Palo Alto, CA, USA). PCR-generated 843bp full length mouse Rasd1 cDNA was inserted into NdeI and EcoRI digested vector pGBKT7 as an in-frame fusion with the DNA binding domain of GAL4 at its 3' end, and the resulting plasmid was designated pGBKT7-Rasd1. The correct insertion of Rasd1 was confirmed by restriction analysis and verified by sequencing. pGBKT7 carries the yeast nutritional selection marker TRP1. Library screening was performed using Rasd1-Gal4 DNA binding domain fusion protein expressed from pGBKT7-Rasd1 as the bait. Absence of autonomous activation of reported genes in yeast was verified by bait before library screening. Mouse brain MATCHMAKER cDNA library culture (Clontech, Palo Alto, CA, USA) was used as prey. The library was cloned into pACT2 vector that encodes for the GAL4 transactivation domain and LEU2 as the yeast nutritional selection marker. Yeast strains used were AH109 and Y187. AH109 contains two nutritional reported genes for adenine and histidine. Yeast transformations were performed using high-efficiency lithium acetate/poly-ethylene glycol method [68]. Yeast AH109 was transformed with pGBKT7-Rasd1 and nutritionally selected on synthetic dropout (SD)-trp plates. Mouse brain cDNA library cloned in pACT2 was then co-transformed into yeast $\mathrm{AH} 109$ that contained pGBKT7-Rasd1 and plated on SD-trp-leu medium to nutritionally select for the presence of both proteins. Putatively positive colonies were selected on SD-ade-histrp-leu plates and assayed for $\beta$-galactosidase activity by use of 5-bromo-4-chloro-3-indolyl- $\beta$-D-galactopyranoside (X-gal) as a substrate. Secondary screens were performed in a similar manner to minimize false positives. Positive colonies were subcultured and grown to saturation in SD-leu medium to expel the bait plasmid. Library plasmids from positive interacting colonies were recovered and sorted into groups according to PCR product sizes with primers MATCHMAKER 5' AD LDInsert screening amplimer and 3' AD LD-Insert screening amplimer and restriction digestion pattern with HpaII. The clones were then sequenced using GAL4 activation domain sequencing primer. BLAST searches (National Centre for Biotechnology Information, NCBI) were performed to identify these clones. The specificity of protein-protein interaction was further tested by yeast mating according to manufacturer's protocol. Y187 was transformed with either pGBKT7Rasd1 or pGBKT7 vector, and nutritionally selected in medium lacking tryptophan. AH109 was transformed with either pACT2-Ear2 or pACT2 vector alone and grown in medium lacking leucine. To verify the putative positive clones, the transformed yeast strain AH109(MATa) were then mated with Y187(MAT $\alpha$ ) and grown in medium lacking tryptophan and leucine.
The cells were then replica plated on SD-ade-his-trpleu and re-assayed for $\beta$-galactosidase activity.

Plasmids- The pHisHA-Rasd1 construct was generated by cloning the $843 \mathrm{bp}$ coding region of Rasd1 into KpnI and EcoRI digested pcDNA4/HisMax ${ }^{\odot} \mathrm{B}$ (Stratagene) vector. Rasd1 was tagged in frame with the 5 ' polyHis tag and Xpress epitope. In addition, a hemagglutinin (HA) tag was added in frame with the coding region of Rasd1 at its 3' terminal using polymerase chain reaction (PCR). Rasd1[ $\triangle \mathrm{CAAX}]$ was also cloned into $K p n \mathrm{I}$ and EcoRI digested $\mathrm{pcDNA} 4 / \mathrm{HisMax}^{\circ} \mathrm{B}$. Site-directed mutagenesis based on overlap extension PCR [69] using two common flanking primers along with individual overlapping mutagenic primers was used to generate the Rasd1 mutant constructs A178V, G81A and T38N. The resulting PCR products were cloned into $K p n I$ and EcoRI digested pcDNA4/HisMax ${ }^{\circ}$ B. pGST-Ear2 construct was generated by cloning the 1173bp Ear2 coding region into pxJGST vector, tagged in frame with a $5^{\prime}$ glutathione-S-transferase (GST) tag with the inFusion cloning kit (Clontech), using NotI restriction site. GSTEar2 truncated constructs carrying DNA sequences corresponding to amino acids 1-193, 1-130, 1-53, 54-390, 131-390 and 194-390 of Ear2 were also cloned into NotI digested pxJGST vector. pxJGST vector was derived from pxJ-FLAG-S vector [70]. p4.1-Luc construct was generated by cloning the $4.1 \mathrm{~kb}$ renin promoter into NheI and HindIII digested pGL3-basic vector (Promega). Rasd1 shRNA knockdown plasmid construct was generated by annealing oligonucleotides targeted at the open reading frame of Rasd1 and inserting the annealed oligonucleotides into BglII and HindIII digested pSUPER. puro (Oligoengine) vector. Control shRNA was generated by inserting randomly jumbled sequences of the Rasd1 shRNA oligonucleotide sequences into BglII and HindIII digested pSUPER.puro. All clones were checked by restriction analysis and verified by sequencing.

Cell culture and Transfection- COS-7 cells (American Type Culture Collection, ATCC CRL-1651) were maintained in RPMI1640 (HyClone). As4.1 cells (ATCC CRL-2193) were maintained in DMEM (ATCC). Neuro2a cells were maintained in MEM (Hyclone). HEK293T cells were maintained in DMEM (Hyclone). All media was supplemented with $10 \% \mathrm{FBS}$, penicillin $(100 \mathrm{U} / \mathrm{mL})$ and streptomycin $(100 \mathrm{mg} / \mathrm{mL})$. Cells $\left(3.0-3.5 \times 10^{5}\right)$ were cultured in each well of 6-well culture plates for 24 hours before transfection. For pulldown assays, confocal studies and experiments that measure endogenous renin levels, cells were transfected with $2.5 \mu \mathrm{g}$ of pGST-Ear2 per well. In co-transfection experiments, pHisHA-Rasd1 $(3.5 \mu \mathrm{g})$ was transfected together with pGST-Ear2 $(2.0 \mu \mathrm{g})$. For luciferase assays, cells were transfected with p4.1-Luc or pGL3-basic $(2.0 \mu \mathrm{g})$, pGST-Ear2 (0.5- $1.5 \mu \mathrm{g})$, pHisHA-Rasd1 
(0.1- $1.5 \mu \mathrm{g})$, pSV- $\beta$-gal $(0.5 \mu \mathrm{g})$ in the combinations as indicated in the figure legends. Total amount of transfected DNA in all transfections were held constant with the appropriate amounts of respective empty vector added to the plasmid mix. shRNA knockdown experiments were performed by transfecting Rasd 1 shRNA or non-targeting control shRNA $(2 \mu \mathrm{g} / \mathrm{ml})$. Selection with puromycin $(2 \mu \mathrm{g} / \mathrm{ml})$ and dexamethasone $(100 \mathrm{nM})$ treatment was carried out 24 hours post transfection, and cells were harvested 48 hours post transfection. Knockdown efficiency was determined by semi-quantitative RT-PCR and Western blotting. Quantification of immunoblots was measured using the GS-800 calibrated densitometer (Bio-Rad). Transfection was carried out with DNA $(\mu \mathrm{g})$ to Lipofectamine 2000 ( $\mu \mathrm{l})$ (Invitrogen) ratio of 1:2, according to manufacturer's instructions.

Protein binding assays- In GST pulldown assays, COS7 cells were transfected separately with pGST-Ear2 and pHisHA-Rasd1. Cells were harvested 40 to 48 hours after transfection and lysed with lysis buffer (1\% TritonX 100, 15\% Glycerol, $1 \mathrm{mM}$ phenylmethylsulphonyl fluoride, $150 \mathrm{mM} \mathrm{NaCl}, 100 \mathrm{mM}$ Tris, $\mathrm{pH}$ 7.4, protease inhibitor (Roche)) for 20 minutes to 1 hour, on a rotating platform, at $4^{\circ} \mathrm{C}$. For cell lysis, $100 \mu \mathrm{l}$ of lysis buffer was added into each well of a 6-well plate. Crude cell lysate was cleared by centrifugation at $13,000 \mathrm{rpm}, 4^{\circ} \mathrm{C}$ for 20 minutes. GST fusion proteins were immobilized on magnetic glutathione (GSH)-linked beads (Promega) by incubating $200 \mu \mathrm{l}$ of the respective crude cell lysate with GSH-linked beads on a rotating platform for 30 minutes at room temperature. The beads were then washed 3 times with binding/washing buffer (Promega) and resuspended in $40 \mu \mathrm{l}$ of the same binding/washing buffer. Cellular lysate $(100 \mu \mathrm{l})$ from pHA-Rasd1 transfected cells was then incubated with the GST-Ear2 proteins immobilized on magnetic GSH-linked beads on a rotating platform for 1 hour, at room temperature, with $1 \%$ bovine serum albumin (BSA) as the blocking reagent. After incubation, the beads were vortexed once, and then washed five times with binding/washing buffer, and bound proteins were eluted from the GSH-linked beads by heating in Laemmli buffer at $95^{\circ} \mathrm{C}$ for 10 minutes.

In co-precipitation assays, COS-7 cells were co-transfected with pHisHA-Rasd1 and pGST-Ear2. Cells were harvested as described above. GST fusion proteins were immobilized on magnetic GSH-linked beads by incubating $200 \mu \mathrm{l}$ of the cleared crude cell lysate with $30 \mu \mathrm{l}$ of GSH-linked beads, with $1 \%$ BSA, on a rotating platform for 1 hour at room temperature. After incubation, the beads were washed four times with binding/washing buffer, and bound proteins were eluted from the GSHlinked beads by heating in Laemmli buffer at $95^{\circ} \mathrm{C}$ for 10 minutes.
Co-immunoprecipitations were performed by first pre-clearing $200 \mu \mathrm{l}$ of crude cell lysate with $4 \mu \mathrm{g}$ of mouse monoclonal $\operatorname{IgG}_{1}$ antibody (anti-c-Myc antibody, Santa Cruz), for 1 hour, on ice. The cell lysate was then incubated with $20 \mu \mathrm{l}$ of protein $\mathrm{G}$ agarose resin beads (Invitrogen), for 30 minutes at $4^{\circ} \mathrm{C}$ on a rotating platform, followed by centrifugation at $14,000 \times \mathrm{g}$ for 10 minutes at $4{ }^{\circ} \mathrm{C}$. The supernatant was incubated with 4 $\mu \mathrm{g}$ of anti-GST antibody overnight, followed by $20 \mu \mathrm{l}$ of resin beads for 1.5 hours, both on a rotating platform at $4^{\circ} \mathrm{C}$. The resin was recovered after centrifugation at $13,000 \mathrm{rpm}$ for 10 minutes at $4^{\circ} \mathrm{C}$, washed once with PBS buffer and bound proteins were finally eluted from the resin beads by heating in Laemmli buffer at $95^{\circ} \mathrm{C}$ for 10 minutes.

Immunoprecipitation of endogenous Rasd1-Ear2 complexes was performed using crude lysate from untransfected HEK293T cells, as well as mouse brain crude lysate. Procedure was similar to co-immunoprecipitation protocol except that the crude cell lysate was precleared with $80 \mu \mathrm{l}$ of protein-G agarose resin beads for 30 minutes at $4{ }^{\circ} \mathrm{C}$. Goat polyclonal IgG anti-Ear2 antibody (Santa Cruz) was used to carry out immunoprecipitation, and a non-relevant goat polyclonal IgG anti-Tdg antibody (Santa Cruz) served as negative control. Immobilization of HisHA-Rasd1 was carried out using Ni-NTA Magnetic agarose beads (Qiagen) according to manufacturer's protocol. The Ni-NTA magnetic beads target the $5^{5}$-polyHis tag present on our HisHARasd1 construct.

Proteins were analyzed using Western blots. Protein samples mixed with $1 \mathrm{X}$ Laemmli buffer were heated at $95^{\circ} \mathrm{C}$ for 10 minutes, separated by $10 \%$ SDS-PAGE, then transferred to polyvinylidene fluoride (PVDF) membranes (Bio-Rad, CA, USA). Blots were blocked in $5 \%$ non-fat milk, overnight at $4{ }^{\circ} \mathrm{C}$. Primary antibodies used included anti-GST mouse monoclonal IgG $_{1}$ (1:5000) (Santa Cruz), anti-HA mouse monoclonal $\operatorname{IgG}_{2 \mathrm{a}}(1: 250)$ (Santa Cruz), anti-Ear2 goat polyclonal IgG (1:250) (Santa Cruz) and goat polyclonal antiRasd1 (1:1000) (Abcam). Secondary antibodies used included sheep anti-mouse horseradish peroxidase (HRP)-linked IgG (1:5000) (Amersham, GE Healthcare, UK) and rabbit anti-goat HRP-linked IgG (Abcam). Detection was performed with Western blot ECL kit detection reagents (Amersham, GE Healthcare, UK). All washes in between incubations are with TBST (0.1\% Tween-20), for three times of 10 minutes each, at room temperature.

Immunofluorescence staining- Transfected COS-7 cells were used for indirect immunofluorescence staining as described [36]. HisHA-Rasd1 was detected with anti-HA antibody and visualized with goat anti-mouse IgG AlexaFluor 568 (Invitrogen). GST-Ear2 was detected and 
visualized with anti-GST AlexaFluor 488 (Santa Cruz) by confocal microscopy (Zeiss). Nuclei were stained by 4',6-diamidino-2-phenylindole (Sigma).

Luciferase reporter assay- Luciferase assays were performed using a Luciferase Assay System (Promega) kit according to manufacturer's protocol. COS-7, Neuro2a or As4.1 cells were co-transfected with pSV- $\beta$-Galactosidase, p4.1-Luc and relevant amounts of Ear2 and Rasd1 constructs. Total DNA concentration was held constant with respective carrier plasmid DNA. Cells were treated with $1 \mu \mathrm{M}$ all-trans retinoic acid at 24 hours post transfection where applicable. Cells were harvested in $1 \mathrm{X}$ reporter lysis buffer (Promega) at 48 hours post transfection. The firefly luciferase activity was measured by a $20 / 20^{\mathrm{n}}$ Luminometer (Turner Biosystems). $\beta$-galactosidase ( $\beta$-gal) levels were measured using $\beta$-Galactosidase Enzyme Assay System (Promega) according to manufacturer's protocol. Luciferase activity was normalized against $\beta$-gal activity. Basal activity of promoterless enhancerless pGL3-basic was set to 100. Relative luciferase activities for all constructs were obtained from dividing normalized values against values obtained from promoter-less pGL3-basic. At least 3 sets of triplicates were conducted for each experiment. For all luciferase reporter assays, statistical analyses were performed using ANOVA or unpaired t-tests. Error bars shown are standard deviations.

Real-time RT-PCR- Total RNA was harvested from As4.1 cells 24 hours or 48 hours post transfection with Trizol reagent (Invitrogen) according to the manufacturer's protocol. The reverse transcription reaction was performed using iScript cDNA synthesis kit (Bio-Rad). Real-time PCR was performed with iTaq SYBR green supermix (Bio-Rad). The cycling conditions are $95^{\circ} \mathrm{C}$ for 15 seconds, $60^{\circ} \mathrm{C}$ for 30 seconds (for renin and G3PDH) or $66.5^{\circ} \mathrm{C}$ for 30 seconds (for Rasd1), $72^{\circ} \mathrm{C}$ for 40 seconds, 40 cycles. The number of PCR cycles for semi-quantitative real time RT-PCR was optimized to ensure that the reactions were in the linear range of amplification (G3PDH for 15 cycles, renin for 19 cycles and Rasd 1 for 21 cycles). The amount of transcribed cDNA was normalized to G3PDH expression with the 7500 Real-time PCR system (Applied Biosystem). Three independent experiments were performed in duplicate.

Refer to Additional file 1 for oligonucleotides used in this study.

\section{Additional material}

Additional File 1: List of oligonucleotides used for cloning and sequencing. Tabulated data of oligonucleotides used in the experiments

\section{Acknowledgements}

This work was supported by grant from the Singapore Ministry of Education, Academic Research Fund Tier 2 (ARC 3/04, M45080000) awarded to KenShiung Chen.

\section{Author details}

${ }^{1}$ School of Biological Sciences, Department of Genomics and Genetics, Nanyang Technological University, 60 Nanyang Drive, 637551, Singapore. ${ }^{2}$ Agency for Science, Technology and Research, 1 Fusionpolis Way, \#20-10 Connexis North Tower, 138632, Singapore.

\section{Authors' contributions}

JJT was involved in the design and execution of all experiments, and drafted the manuscript. SAO was involved in the knockdown and confocal studies, and edited the manuscript. K-SC conceived of the study, and participated in its design and coordination and edited the manuscript. All authors read and approved the final manuscript.

Received: 1 November 2010 Accepted: 19 January 2011

Published: 19 January 2011

\section{References}

1. Nishimura $H$, Ichikawa I: What have we learned from gene targeting studies for the renin angiotensin system of the kidney? Intern Med 1999, 38:315-323.

2. Harrison-Bernard LM: The renal renin-angiotensin system. Adv Physiol Educ 2009, 33:270-274.

3. von Bohlen und Halbach $\mathrm{O}$ : The renin-angiotensin system in the mammalian central nervous system. Curr Protein Pept Sci 2005, 6:355-371.

4. Sinn $P L$, Sigmund $C D$ : Human renin mRNA stability is increased in response to CAMP in Calu-6 cells. Hypertension 1999, 33:900-905.

5. Lang JA, Ying LH, Morris BJ, Sigmund CD: Transcriptional and posttranscriptional mechanisms regulate human renin gene expression in Calu-6 cells. Am J Physiol 1996, 271:F94-100.

6. Petrovic N, Black TA, Fabian JR, Kane C, Jones CA, Loudon JA, Abonia JP, Sigmund CD, Gross KW: Role of proximal promoter elements in regulation of renin gene transcription. J Biol Chem 1996, 271:22499-22505.

7. Shi Q, Black TA, Gross KW, Sigmund CD: Species-specific differences in positive and negative regulatory elements in the renin gene enhancer. Circ Res 1999, 85:479-488

8. Yan Y, Jones CA, Sigmund CD, Gross KW, Catanzaro DF: Conserved enhancer elements in human and mouse renin genes have different transcriptional effects in As4.1 cells. Circ Res 1997, 81:558-566.

9. Shi Q, Gross KW, Sigmund CD: Retinoic acid-mediated activation of the mouse renin enhancer. J Biol Chem 2001, 276:3597-3603.

10. Shi Q, Gross KW, Sigmund CD: NF-Y antagonizes renin enhancer function by blocking stimulatory transcription factors. Hypertension 2001, 38:332-336.

11. Pan L, Black TA, Shi Q, Jones CA, Petrovic N, Loudon J, Kane C, Sigmund $C D$, Gross KW: Critical roles of a cyclic AMP responsive element and an E-box in regulation of mouse renin gene expression. $J$ Biol Chem 2001, 276:45530-45538.

12. Pan L, Gross KW: Transcriptional regulation of renin: an update. Hypertension 2005, 45:3-8.

13. Liu $X$, Huang $X$, Sigmund CD: Identification of a nuclear orphan receptor (Ear2) as a negative regulator of renin gene transcription. Circ Res 2003, 92:1033-1040.

14. Tsai SY, Tsai MJ: Chick ovalbumin upstream promoter-transcription factors (COUP-TFs): coming of age. Endocr Rev 1997, 18:229-240.

15. Cooney AJ, Tsai SY, O'Malley BW, Tsai MJ: Chicken ovalbumin upstream promoter transcription factor (COUP-TF) dimers bind to different GGTCA response elements, allowing COUP-TF to repress hormonal induction of the vitamin D3, thyroid hormone, and retinoic acid receptors. Mol Cell Biol 1992, 12:4153-4163.

16. Ladias JA, Hadzopoulou-Cladaras M, Kardassis D, Cardot P, Cheng J, Zannis $V$, Cladaras C: Transcriptional regulation of human apolipoprotein genes $A p o B, A p o C I I I$, and ApoAll by members of the steroid hormone receptor superfamily HNF-4, ARP-1, EAR-2, and EAR-3. J Biol Chem 1992, 267:15849-15860. 
17. Chu K, Zingg HH: The nuclear orphan receptors COUP-TFII and Ear-2 act as silencers of the human oxytocin gene promoter. $J \mathrm{Mol}$ Endocrinol 1997, 19:163-172.

18. Zhang $Y$, Dufau ML: Nuclear orphan receptors regulate transcription of the gene for the human luteinizing hormone receptor. J Biol Chem 2000, 275:2763-2770.

19. Zhu XG, Park KS, Kaneshige M, Bhat MK, Zhu Q, Mariash CN, McPhie P, Cheng SY: The orphan nuclear receptor Ear-2 is a negative coregulator for thyroid hormone nuclear receptor function. Mol Cell Biol 2000 20:2604-2618.

20. Kastner P, Mark M, Chambon P: Nonsteroid nuclear receptors: what are genetic studies telling us about their role in real life? Cell 1995, 83:859-869.

21. Mangelsdorf DJ, Thummel C, Beato M, Herrlich P, Schutz G, Umesono K, Blumberg B, Kastner P, Mark M, Chambon P, Evans RM: The nuclear receptor superfamily: the second decade. Cell 1995, 83:835-839.

22. Leng X, Cooney AJ, Tsai SY, Tsai MJ: Molecular mechanisms of COUP-TFmediated transcriptional repression: evidence for transrepression and active repression. Mol Cell Biol 1996, 16:2332-2340.

23. Aranda A, Pascual A: Nuclear hormone receptors and gene expression. Physiol Rev 2001, 81:1269-1304.

24. Duez $H$, Staels B: Nuclear receptors linking circadian rhythms and cardiometabolic control. Arterioscler Thromb Vasc Biol 2010, 30:1529-1534.

25. Warnecke M, Oster H, Revelli JP, Alvarez-Bolado G, Eichele G: Abnormal development of the locus coeruleus in Ear2(Nr2f6)-deficient mice impairs the functionality of the forebrain clock and affects nociception. Genes Dev 2005, 19:614-625.

26. Jonk LJ, de Jonge ME, Pals CE, Wissink S, Vervaart JM, Schoorlemmer J, Kruijer W: Cloning and expression during development of three murine members of the COUP family of nuclear orphan receptors. Mech Dev 1994, 47:81-97.

27. Miyajima N, Kadowaki Y, Fukushige S, Shimizu S, Semba K, Yamanashi Y, Matsubara K, Toyoshima K, Yamamoto T: Identification of two novel members of erbA superfamily by molecular cloning: the gene products of the two are highly related to each other. Nucleic Acids Res 1988, 16:11057-11074.

28. Kemppainen $\mathrm{RJ}$, Behrend EN: Dexamethasone rapidly induces a novel ras superfamily member-related gene in AtT-20 cells. J Biol Chem 1998, 273:3129-3131

29. Takahashi H, Umeda N, Tsutsumi Y, Fukumura R, Ohkaze $H$, Sujino M, van der Horst G, Yasui A, Inouye ST, Fujimori A, et al: Mouse dexamethasoneinduced RAS protein 1 gene is expressed in a circadian rhythmic manner in the suprachiasmatic nucleus. Brain Res Mol Brain Res 2003, 110:1-6

30. Fang M, Jaffrey SR, Sawa A, Ye K, Luo X, Snyder SH: Dexras1: a G protein specifically coupled to neuronal nitric oxide synthase via CAPON. Neuron 2000, 28:183-193.

31. Cheng HY, Obrietan K: Dexras1: shaping the responsiveness of the circadian clock. Semin Cell Dev Biol 2006, 17:345-351.

32. Jones CA, Sigmund CD, McGowan RA, Kane-Haas CM, Gross KW: Expression of murine renin genes during fetal development. Mol Endocrinol 1990, 4:375-383

33. Sigmund $C D$, Okuyama $K$, Ingelfinger J, Jones $C A$, Mullins JJ, Kane C, Kim U, Wu CZ, Kenny L, Rustum Y, et al: Isolation and characterization of reninexpressing cell lines from transgenic mice containing a renin-promoter viral oncogene fusion construct. J Biol Chem 1990, 265:19916-19922.

34. Colicelli J: Human RAS superfamily proteins and related GTPases. SCi STKE 2004, 2004:RE13.

35. Lowy DR, Willumsen BM: Function and regulation of ras. Annu Rev Biochem 1993, 62:851-891.

36. Lau K-F, Chan W-M, Perkinton MS, Tudor EL, Chang RCC, Chan HYE, McLoughlin DM, Miller CCJ: Dexras1 Interacts with FE65 to Regulate FE65-Amyloid Precursor Protein-dependent Transcription. J Biol Chem 2008, 283:34728-34737.

37. Dever TE, Glynias MJ, Merrick WC: GTP-binding domain: three consensus sequence elements with distinct spacing. Proc Natl Acad Sci USA 1987, 84:1814-1818

38. Hwang MC, Sung YJ, Hwang YW: The differential effects of the Gly- 60 to Ala mutation on the interaction of $\mathrm{H}$-Ras p21 with different downstream targets. J Biol Chem 1996, 271:8196-8202.
39. Chen SY, Huff SY, Lai CC, Der CJ, Powers S: Ras-15A protein shares highly similar dominant-negative biological properties with Ras-17N and forms a stable, guanine-nucleotide resistant complex with CDC25 exchange factor. Oncogene 1994, 9:2691-2698.

40. Feig LA, Cooper GM: Inhibition of NIH $3 \mathrm{~T} 3$ cell proliferation by a mutant ras protein with preferential affinity for GDP. Mol Cell Biol 1988, 8:3235-3243.

41. Okamura T, Clemens DL, Inagami T: Renin, angiotensins, and angiotensinconverting enzyme in neuroblastoma cells: evidence for intracellular formation of angiotensins. Proc Natl Acad Sci USA 1981, 78:6940-6943.

42. Graham TE, Key TA, Kilpatrick K, Dorin RI: Dexras1/AGS-1, a steroid hormone-induced guanosine triphosphate-binding protein, inhibits $3^{\prime}, 5^{\prime}$-cyclic adenosine monophosphate-stimulated secretion in AtT-20 corticotroph cells. Endocrinology 2001, 142:2631-2640.

43. Sung YJ, Carter M, Zhong JM, Hwang YW: Mutagenesis of the H-ras p21 at glycine-60 residue disrupts GTP-induced conformational change. Biochemistry 1995, 34:3470-3477.

44. Kjaersgard IV, Knudsen CR, Wiborg O: Mutation of the conserved Gly83 and Gly94 in Escherichia coli elongation factor Tu. Indication of structural pivots. Eur J Biochem 1995, 228:184-190.

45. Guo H, Brewer JM, Champhekar A, Harris RB, Bittman EL: Differential control of peripheral circadian rhythms by suprachiasmatic-dependent neural signals. Proc Natl Acad Sci USA 2005, 102:3111-3116.

46. Pando MP, Morse D, Cermakian N, Sassone-Corsi P: Phenotypic rescue of a peripheral clock genetic defect via SCN hierarchical dominance. Cell 2002, 110:107-117.

47. Silver R, LeSauter J, Tresco PA, Lehman MN: A diffusible coupling signal from the transplanted suprachiasmatic nucleus controlling circadian locomotor rhythms. Nature 1996, 382:810-813.

48. Teboul M, Grechez-Cassiau A, Guillaumond F, Delaunay F: How nuclear receptors tell time. J Appl Physiol 2009.

49. Wright JW, Harding JW: Brain angiotensin receptor subtypes in the control of physiological and behavioral responses. Neurosci Biobehav Rev 1994, 18:21-53.

50. Lavoie JL, Liu X, Bianco RA, Beltz TG, Johnson AK, Sigmund CD: Evidence supporting a functional role for intracellular renin in the brain. Hypertension 2006, 47:461-466.

51. Grobe $J, X u$ D, Sigmund $C D$ : An intracellular renin-angiotensin system in neurons: fact, hypothesis, or fantasy. Physiology (Bethesda) 2008, 23:187-193.

52. Wright JW, Reichert JR, Davis CJ, Harding JW: Neural plasticity and the brain renin-angiotensin system. Neurosci Biobehav Rev 2002, 26:529-552.

53. Emeric-Sauval E: Corticotropin-releasing factor (CRF)-a review. Psychoneuroendocrinology 1986, 11:277-294.

54. Kiss A, Jurkovicova D, Jezova D, Krizanova O: Changes in angiotensin AT1 receptor $\mathrm{mRNA}$ levels in the rat brain after immobilization stress and inhibition of central nitric oxide synthase. Endocr Regul 2001, 35:65-70.

55. Watanabe T, Fujioka T, Hashimoto M, Nakamura S: Stress and brain angiotensin II receptors. Crit Rev Neurobiol 1998, 12:305-317.

56. Dumont EC, Rafrafi S, Laforest S, Drolet G: Involvement of central angiotensin receptors in stress adaptation. Neuroscience 1999, 93:877-884.

57. Amouyel P, Richard F, Berr C, David-Fromentin I, Helbecque N: The renin angiotensin system and Alzheimer's disease. Ann N Y Acad Sci 2000, 903:437-441.

58. Barnes NM, Cheng CH, Costall B, Naylor RJ, Williams TJ, Wischik CM: Angiotensin converting enzyme density is increased in temporal cortex from patients with Alzheimer's disease. Eur J Pharmacol 1991, 200:289-292.

59. Savaskan E, Hock C, Olivieri G, Bruttel S, Rosenberg C, Hulette C, MullerSpahn F: Cortical alterations of angiotensin converting enzyme, angiotensin II and AT1 receptor in Alzheimer's dementia. Neurobiol Aging 2001, 22:541-546.

60. Ge J, Towers P, Patel AC, Barnes NM: [125I]S(-)-zacopride labels a novel 5hydroxytryptamine sensitive recognition site in rat duodenum and ileum. Eur J Pharmacol 1996, 300:113-117.

61. Lin JJ, Yueh KC, Chang DC, Lin SZ: Association between genetic polymorphism of angiotensin-converting enzyme gene and Parkinson's disease. J Neurol Sci 2002, 199:25-29.

62. Turini GA, Brunner HR, Gribic M, Waeber B, Gavras H: Improvement of chronic congestive heart-failure by oral captopril. Lancet 1979, 1:1213-1215 
63. Jeunemaitre X, Soubrier F, Kotelevtsev Y, Lifton RP, Williams CS, Charru A, Hunt SC, Hopkins PN, Williams RR, Lalouel JM, et al: Molecular basis of human hypertension: role of angiotensinogen. Cell 1992, 71:169-180.

64. Rapp JP, Wang SM, Dene H: A genetic polymorphism in the renin gene of Dahl rats cosegregates with blood pressure. Science 1989, 243:542-544.

65. Brunner HR, Gavras H, Waeber B, Kershaw GR, Turini GA, Vukovich RA, McKinstry DN, Gavras I: Oral angiotensin-converting enzyme inhibitor in long-term treatment of hypertensive patients. Ann Intern Med 1979, 90:19-23.

66. Brunner HR, Gavras H, Waeber B, Turini GA, McKinstry DN, Vukovich RA, Gavras I: Orally active angiotensin-converting enzyme inhibitor (SO 14,225) as a treatment for essential hypertension. $\mathrm{Br} J$ Clin Pharmacol 1979, 7(2):205S-211S

67. Tifft CP, Gavras H, Kershaw GR, Gavras I, Brunner HR, Liang CS, Chobanian AV: Converting enzyme inhibition in hypertensive emergencies. Ann Intern Med 1979, 90:43-47.

68. Gietz RD, Woods RA: Transformation of yeast by lithium acetate/singlestranded carrier DNA/polyethylene glycol method. Methods Enzymol 2002, 350:87-96.

69. Ho SN, Hunt HD, Horton RM, Pullen JK, Pease LR: Site-directed mutagenesis by overlap extension using the polymerase chain reaction. Gene 1989, 77:51-59.

70. Manser E, Huang HY, Loo TH, Chen XQ, Dong JM, Leung T, Lim L: Expression of constitutively active alpha-PAK reveals effects of the kinase on actin and focal complexes. Mol Cell Biol 1997, 17:1129-1143.

doi:10.1186/1471-2199-12-4

Cite this article as: Tan et al:: Rasd1 interacts with Ear2 (Nr2f6) to regulate renin transcription. BMC Molecular Biology 2011 12:4.

\section{Submit your next manuscript to BioMed Central and take full advantage of:}

- Convenient online submission

- Thorough peer review

- No space constraints or color figure charges

- Immediate publication on acceptance

- Inclusion in PubMed, CAS, Scopus and Google Scholar

- Research which is freely available for redistribution

Submit your manuscript at www.biomedcentral.com/submit 